\title{
ENDOCRINAL ASSOCIATION OF HYPOTHALAMIC-PITUITARY-ADRENAL (HPA) AXIS WITH OBESITY
}

\author{
Kaynaat Sohail \\ Department of Biochemistry and Biotechnology, The Women University Multan \\ Umm E Aiman \\ Department of Biochemistry and Biotechnology, The Women University Multan \\ Sidra Younis \\ Department of Biological Sciences, National University of Medical Sciences, Rawalpindi \\ Farah Deeba* \\ Department of Biochemistry and Biotechnology, The Women University Multan
}

\begin{abstract}
Obesity is a serious health condition that has been affecting individuals of all ages worldwide. Dysregulation of the hypothalamic-pituitary-adrenal (HPA) axis and chronic stress exposure are implicated as main contributing factors for obesity development. This study is a systematic review of the research, based on all possible pathways that are involved in obesity involving HPA. The arcuate nucleus (ARC) and paraventricular nucleus (PVN) are involved in the interaction of HPA activity and energy intake. Neuropeptide Y and corticotrophin-releasing hormone $(\mathrm{CRH})$ regulate the feeding behavior. Insulin and leptin levels also affect the HPA axis through different pathways and play a significant role in the pathogenesis of obesity. This review shows the relationship of the HPA axis with obesity. By decreasing the activation or by inhibition of different pathways the causes of obesity can be controlled. Recent therapies are being developed to decrease food intake and body weight regulations.
\end{abstract}

Keyword: HPA axis, obesity, neuropeptide Y, glucocorticoid, insulin, leptin

\section{Introduction}

In human's obesity is a major common pathological process. Obesity occurs due to stress, environmental and genetic factors, and now become a serious consequence for health (Aguilar et al., 2011). Nowadays the increasing ratio of obesity is mainly related to the sedentary lifestyle and dietary factors (González et al., 2012). The most important reason for this pandemic health problem is the increased consumption of food rich in saturated fats, carbohydrates, and decreased intake of vegetables (Lange et al., 2011).

Furthermore, the major health consequences of obesity are cardiac and vascular diseases, atherosclerosis due to lipid metabolism changes, changes in hormones that have high metabolic activity like insulin cause cellular insulin resistance, increased risk of Diabetes mellitus type 2 due to decreased glucose tolerance, increased stroke risk due to high blood pressure, hyperleptinemia, and deficiency of growth hormone. These changes are collectively called metabolic syndrome (Juonala et al., 2011). 
Commonly obesity occurs due to the dysregulation of energy balance when energy intake exceeds the expenditure of energy and excessive energy is stored as fats (Tremblay et al., 2004). Modern society elements like western diet stress, depression, and sedentary lifestyle all may dysregulate the HPA axis and cause a positive energy balance and contribute to the development of obesity. HPA axis is an important neuroendocrine axis that plays a significant part in the regulation of energy balance and stress response by the regulated secretion of glucocorticoid like cortisol (Tsigos et al., 2002).

\section{Hypothalamic-pituitary-adrenal (HPA) Axis}

The key adaptive neuroendocrine system of the human body is Hypothalamic-pituitary-adrenal (HPA) axis. Adrenocorticotrophic hormone (ACTH) regulates the glucocorticoid secretion that is critical to life and is much essential to maintain energy balance and mammalian response to stressors (Pedersen et al., 2001; McEwen, 2007; Lupien et al., 2011).

The HPA axis has main components that regulate each other through their secretions like paraventricularis hypothalamic (PVN) that secretes corticotrophin-releasing hormone and arginine vasopressin (AVP). The secretion of PVN and AVP stimulates the pituitary gland which releases ACTH, then with the stimulation of ACTH, the cortex of adrenal gland secretes cortisol in humans and corticosterone in rodents (Yen et al., 1998; Wolkowitz et al., 2009).

Sequentially, in a negative feedback loop, glucocorticoids act through the pituitary and limbic structures mainly the hippocampus to regulate the activity of the neuron that produces CRH in the PVN and thus regulate the whole HPA axis (Bale et al., 2004; Roper et al., 2011). After the release of cortisol, it is transported in circulation and directed to the target peripheral tissue after binding to the corticosteroid-binding globulins, where the activity of $11 \beta$ hydroxysteroid dehydrogenase (11/-HSD) enzyme decides its availability. The inactive cortisone is converted into active cortisol by $11 \beta$-HSD1 isoform and cortisol is converted into inactive cortisone with the help of 11 $\beta$-HSD2 isoform (Nieuwenhuizen and Rutters, 2008). 


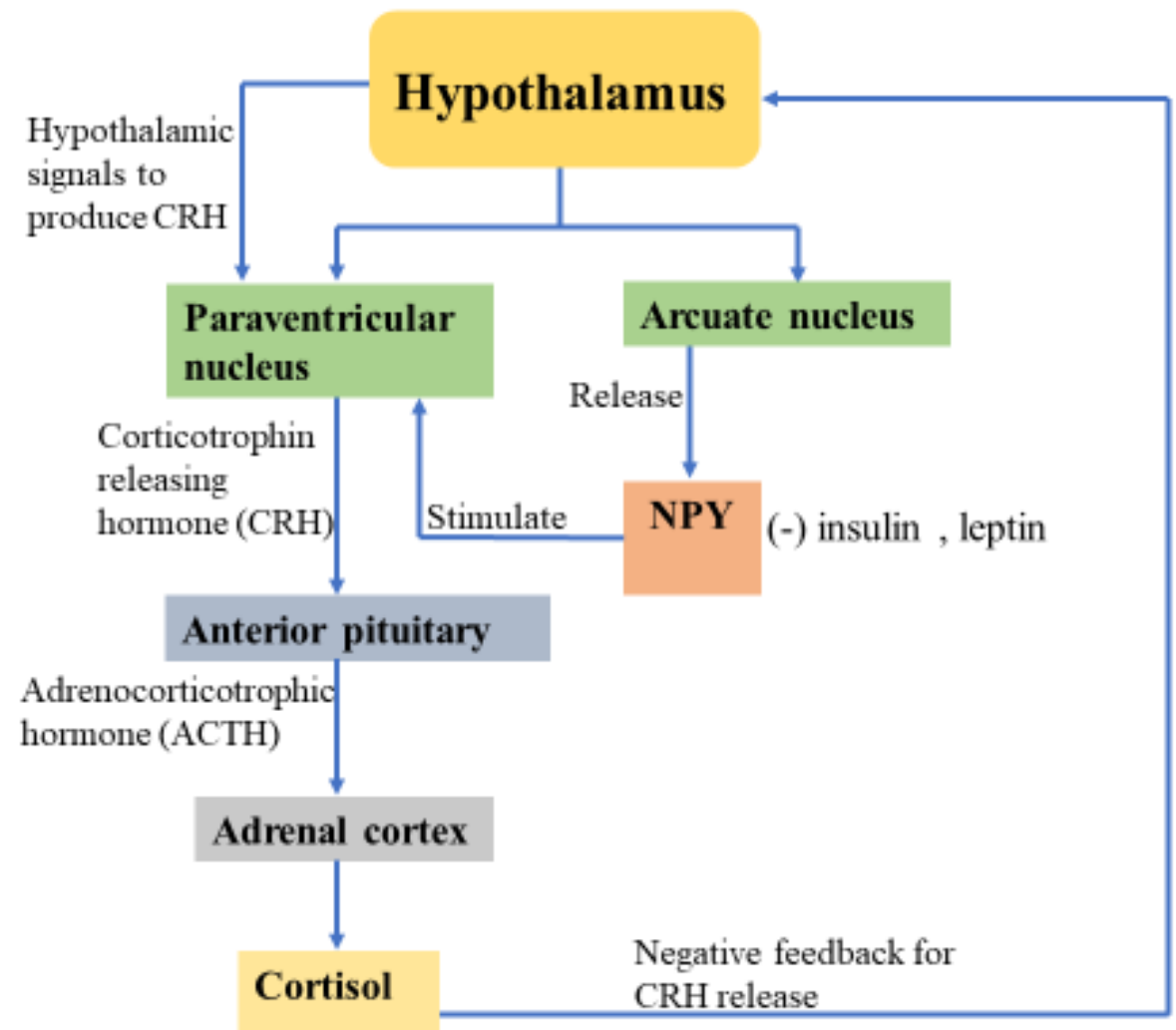

Fig 1: Regulation of glucocorticoid secretion through hypothalamus.

\section{Regulations of HPA Axis in food intake}

The HPA axis activity is managed by the complex interaction of cortisol with central intra and extra hypothalamic sites (Warne, 2009) the intra hypothalamic sites like arcuate nucleus (ARC) and paraventricular nucleus $(\mathrm{PVN})$ are involved in the interaction of HPA activity and energy intake. Glucocorticoid receptors are frequently present in both PVN and ARC (Reul and De Kloet, 1986). Both play a regulatory role in energy intake regulation (Könner et al., 2007; Obici et al., 2002), through the activation of ARC afferents, signals that represents the nutritional status rushes toward the PVN directly or indirectly through neuroendocrine output signals then PVN stimulates gut hormone release including oxytocin, vasopressin, and CRH (Tasker, 2006). The PVN receives its foremost input from ARC, where Neuropeptide Y(NPY) and Agouti-related peptide (AGRP) are co-localized (Hahn et al., 1998).

NPY and AGRP are orexigenic peptide hormones, however NPY neurons stimulate the CRH neurons in PVN and CRH release is activated that eventually stimulate glucocorticoid release that in turn decrease the hypothalamic CRH release and stimulate NPY activity, thus favor energy intake stimulation, forming a positive feedback loop (Warne, 2009). The interaction between orexigenic NPY neurons and anorexigenic CRH is necessary for the maintenance of healthy body weight' the biochemical mechanism of stress eating is due to increased NPY 
concentration in response to stress. Obesity is caused due to this NPY increased concentration in stressed people (Dube et al., 2007).

The receptor for insulin and leptin regulates NPY/AGRP neurons both are present abundantly in ARC (Schwartz, 2000). Leptin and insulin signals inhibit the NPY/AGRP neurons and these neurons are activated under low concentration of insulin and leptin (Hahn et al., 1998; Sipols et al., 1995).

\section{Neuroendocrinal association of insulin and leptin with HPA axis}

\section{Association of insulin}

The receptors of glucocorticoids are excessively present in both PVN and ARC (Reul and De Kloet, 1986). Leptin and insulin circulate in proportion to body fat mass, in ARC they carry the signals for the energy status of the body. When the energy stores of the body are low, the concentration of insulin and leptin will also be low, which eliminates the inhibition within ARC, and feeding behavior is stimulated. Thus, insulin act on orexigenic NPY/AGRP neurons and directly inhibit them while exciting the anorexigenic POMC/cocaine \& amphetamine-regulated transcript (CART) (Schwartz et al., 2003). On the central and peripheral level glucocorticoid interfere with the signaling of insulin. Centrally, glucocorticoids stimulate energy intake by reducing the antagonizing effect of insulin on NPY neurons (Sato et al., 2005). In the periphery, the constant concentrations of glucocorticoid are related to the increases in plasma insulin concentration (la Fleur et al., 2004).

Chronically augmented glucocorticoid results in diabetogenic effects not only through hyperinsulinemia but they also impair the insulin-induced translocation of intracellular glucose transporters and by interacting with receptor binding in the skeletal and liver muscles (Yi et al., 2012). Eliminating or reducing insulin action (either by insulin deficiency or insulin resistance) eradicates the inhibitory effect and glucocorticoids stimulate feeding behavior (la Fleur et al., 2004). Insulin resistance causes NPY to increase that increases feeding and lead to obesity. 


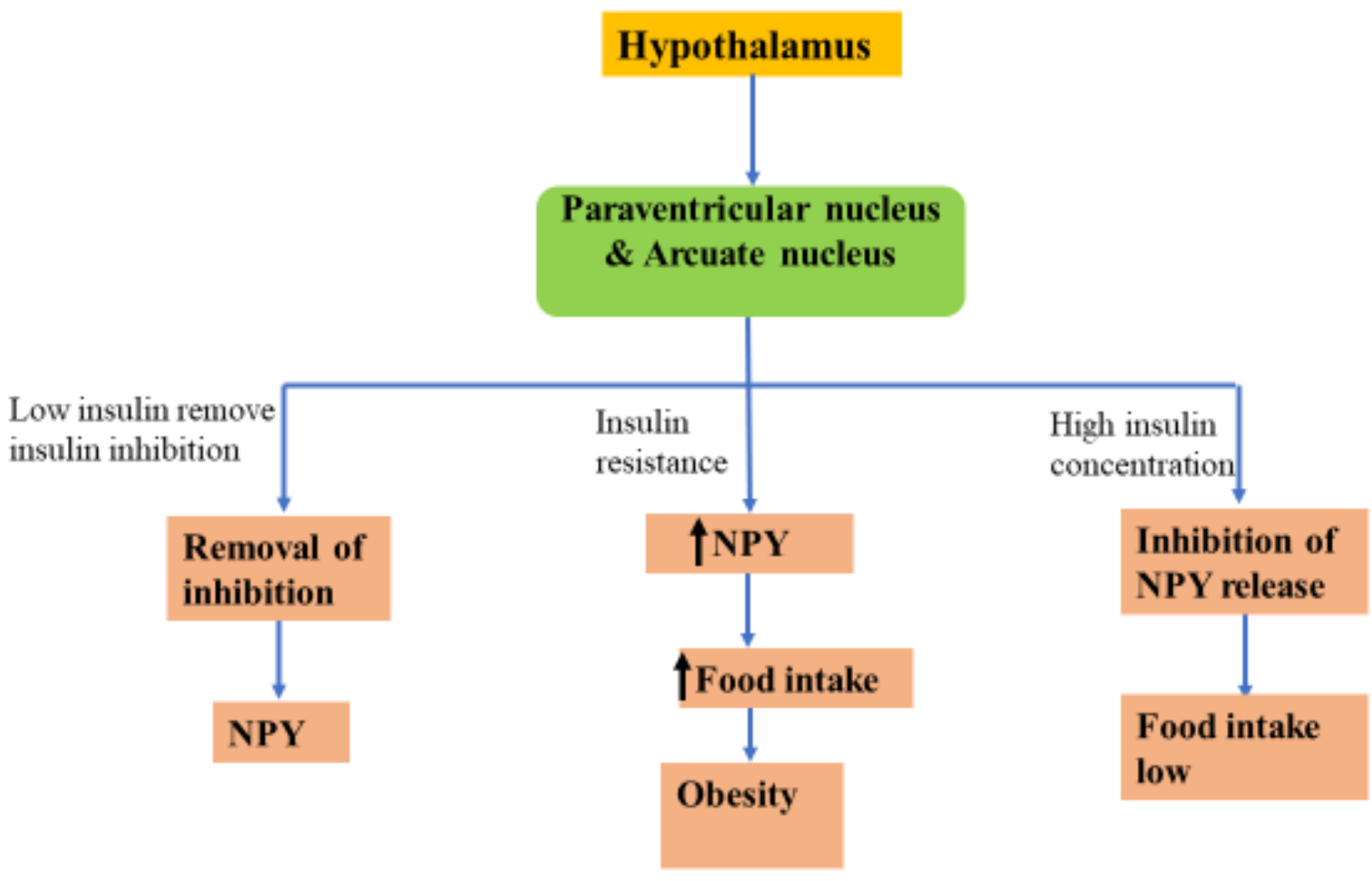

Fig 2: Neuroendocrinal association of insulin

\section{Association of leptin}

Leptin is an adipokine secreted by adipocytes characterized by Friedman et al. Leptin is a protein that is codified by ob gene (Zhang et al., 1994). Leptin derived from Greek word leptos means lean and has a molecular mass of $16 \mathrm{kDa}$, made of 167 amino acids. Energy metabolism is regulated by leptin, it increases energy expenditure. Leptin is a metabolic signal for energy sufficiency (Maffei et al., 1995).

There is a hypothesis that within hypothalamus leptin influences neuropeptides that are involved in the intake of food and energy expenditure, including neuropeptide Y(NPY) and corticotrophin release hormone (CRH) (Campfield et al., 1995; Rohner-Jeanrenaud et al., 1996; Schwartz et al., 1996; Stephens et al., 1995; Wang et al., 1997). NPY causes an increase in food intake and decreases the expenditure of energy (Billington et al., 1994; Clark et al., 1984), while the action of CRH is opposite (Krahn et al., 1988; Rohner-jeanrenaud et al., 1989). Leptin modulates energy balance by decreases the synthesis and secretion of NPY and it increases the synthesis and secretion of $\mathrm{CRH}$.

Leptin level is low during the day while it increases during sleep, so leptin level shows circadian rhythms (Sinha et al., 1996). It is postulated that the rise of leptin at night suppresses the appetite. Sleep deprivation causes a vigorous decrease in leptin levels (Knutson and Van Cauter, 2008). Routine short sleep durations are correlated with 
low leptin in the morning, which probably leads to an increase in appetite through the activation of ARC in the hypothalamus and successively increases food intake (Taheri et al., 2004). This reduction in leptin level may stimulate the intake of food and eventually increases the risk for obesity and metabolic diseases.

The decreased level of circulating soluble leptin receptors (SLR) is associated with obesity (Ogier et al., 2002). These receptors are protein in nature and they circulate in blood and are directly related to leptin function (Ogier et al., 2002; Elmquist et al., 1999). This state explains the resistance to leptin in obese patients because they have high leptin level and low SLR (Holm et al., 2011; Levin et al., 2004). Decreased transport of leptin across blood brain barrier and decreased capability of leptin to initiate hypothalamic signaling in diet induced obesity (Caro et al., 1996; El-Haschimi et al., 2000; Rhee et al., 2011; De Lartigue et al., 2011) may be critical factor in the pathological process of leptin resistance that leads to failure to moderately compensate for positive energy balance that leads to obesity and unwanted weight gain.

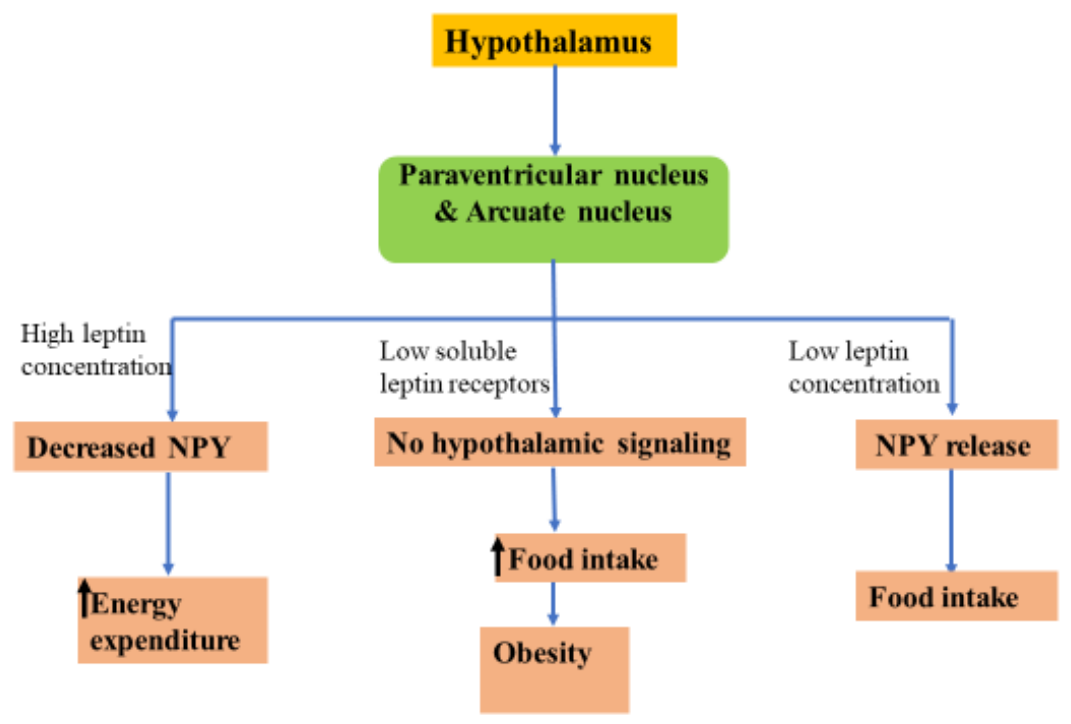

Fig 3: Neuroendocrinal association of leptin

\section{Novel therapies for obesity}

Recent pharmacological approaches to prevent obesity through manipulations of the HPA axis have attention on 11 $\beta$-HSD inhibitors that allow tissue-specific variations in the concentrations of cortisol without affecting

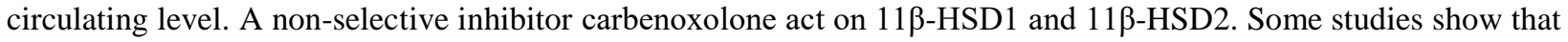
this inhibitor lowers the expression of 11ß-HSD1 in adipose tissues while some do not (Sandeep et al., 2005; Pereira et al., 2012). One study shows that after 7 days administration of $300 \mathrm{mg}$ carbenoxolone reduces glycogenolysis and lowers the cholesterol level (Andrews et al., 2003). 
Topiramate produced a successive weight reduction in an obese patient. Topiramate causes weight loss by increasing the expenditure of energy, an appetite suppressant by decreasing caloric intake, and decrease energetic efficiency (Richard et al., 2000).

Genetically deleted and pharmacologically blocked NPY Y1 and Y5 receptors help to reduce weight and reduce food intake (Erondu et al., 2006). A selective antagonist for NPY Y5 receptor S-2367, known as velneperit induces weight loss (Sargent and Moore et al., 2009). It inhibits the binding of NPY to receptor and satiety induced.

GLP-1 (Glucagon-like peptide 1) receptors are present in brain activity through various neural circuitry involving peripheral GLP-1 signaling control body weight and food consumption regulations (Kanoski et al., 2016). Liraglutide (3.0 mg once-daily subcutaneous), is a GLP-1 analog and recently approved for the obesity treatment (Davies et al., 2015; Wadden et al., 2015).

\section{Conclusion}

Obesity occurs due to the dysregulation of energy balance. HPA axis produce orexigenic NPY and anorexigenic CRH that regulates energy balance. Insulin and leptin circulate in proportion to body fat mass, in ARC they carry the signals for the energy status of the body. Insulin and leptin have an inhibitory effect on NPY neurons. Their circulatory level determines the food intake or energy sufficiency. Insulin resistance and leptin resistance cause the increased food intake to lead to obesity. In the periphery inactive cortisone is converted into active cortisol by $11 \beta$ HSD1 isoform and cortisol is converted into inactive cortisone with the help of 11ß-HSD2 isoform. The over-activity of these enzymes can cause obesity by disturbing the food intake balances. A non-selective inhibitor carbenoxolone

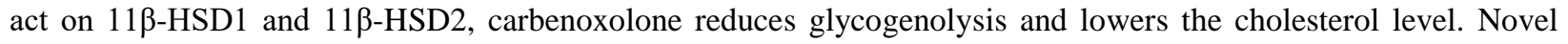
pharmacological studies show that the drugs like topiramate help to lose weight and future researches helps to produce targeted drugs that target the HPA axis for the control of obesity.

\section{References}

Aguilar, Cordero. M., González, J. E., García, G. C. J., López, G., Álvarez, F. J., Padilla, L. C. A., González, M. J. L. \& Ocete, H. E. 2011. Obesidad de una población de escolares de Granada: evaluación de la eficacia de una intervención educativa. Nutrición Hospitalaria, 26(3): 636-641.

Andrews, R. C., Rooyackers, O. \& Walker, B. R. 2003. Effects of the $11 \beta$-hydroxysteroid dehydrogenase inhibitor carbenoxolone on insulin sensitivity in men with type 2 diabetes. The Journal of Clinical Endocrinology \& Metabolism, 88(1): 285-291.

Bale, T. L. \& Vale, W. W. 2004. CRF and CRF receptors: role in stress responsivity and other behaviors. Annual Review of Pharmacology \& Toxicology, 44: 525-557.

Billington, C. J., Briggs, J. E., Harker, S., Grace, M. \& Levine, A. S. 1994. Neuropeptide Y in hypothalamic paraventricular nucleus: a center coordinating energy metabolism. American Journal of PhysiologyRegulatory, Integrative and Comparative Physiology, 266(6): R1765-1770. 
Campfield, L. A., Smith, F. J., Guisez, Y., Devos, R. \& Burn, P. 1995. Recombinant mouse OB protein: evidence for a peripheral signal linking adiposity and central neural networks. Science, 269(5223):v546-549.

Caro, J. F., Kolaczynski, J. W., Nyce, M. R., Ohannesian, J. P., Opentanova, I., Goldman, W. H., Lynn, R. B., Zhang, P. L. \& Sinha, M. K. Considine, R. V. 1996. Decreased cerebrospinal-fluid/serum leptin ratio in obesity: a possible mechanism for leptin resistance. The Lancet, 348(9021): 159-161.

Clark, J. T., Kalra, P. S., Crowley, W. R. \& Kalra, S. P. 1984. Neuropeptide Y and human pancreatic polypeptide stimulate feeding behavior in rats. Endocrinology, 115(1): 427-429.

Davies, M. J., Bergenstal, R., Bode, B., Kushner, R. F., Lewin, A., Skjøth, T. V., Andreasen, A. H., Jensen, C. B. \& DeFronzo, R. A. 2015. Efficacy of liraglutide for weight loss among patients with type 2 diabetes: the SCALE diabetes randomized clinical trial. Jama, 314(7): 687-699.

De Lartigue, G., Barbier, de la., Serre, C., Espero, E., Lee, J. \& Raybould, H. E. 2011. Diet-induced obesity leads to the development of leptin resistance in vagal afferent neurons. American Journal of PhysiologyEndocrinology and Metabolism, 301(1): E187-195.

Dube, M. G., Kalra, S. P. \& Kalra, P. S. 2007. Low abundance of NPY in the hypothalamus can produce hyperphagia and obesity. Peptides. 28(2): 475-479.

El-Haschimi,. K, Pierroz, D. D., Hileman, S. M., Bjørbæk, C. \& Flier, J. S. 2000. Two defects contribute to hypothalamic leptin resistance in mice with diet-induced obesity. The Journal of clinical investigation, 105(12): 1827-1832.

Elmquist, J. K., Elias, C. F. \& Saper, C. B. 1999. Hypothalamic control of body weight. Neuron, 22: $221-232$.

Erondu, N., Gantz, I., Musser, B., Suryawanshi, S., Mallick, M., Addy, C., Cote, J., Bray, G., Fujioka, K., Bays, H. \& Hollander, P. 2006. Neuropeptide Y5 receptor antagonism does not induce clinically meaningful weight loss in overweight and obese adults. Cell metabolism, 4(4): 275-282.

González, J. E., Aguilar, C. M., García, G. C. J., García, L. P., Álvarez, F. J., Padilla, L. C. A. \& Ocete H. E. 2012. Influencia del entorno familiar en el desarrollo del sobrepeso y la obesidad en una población de escolares de Granada (España). Nutrición Hospitalaria, 27(1): 177-184.

Hahn, T. M., Breininger, J. F., Baskin, D. G. \& Schwartz, M. W. 1998. Coexpression of Agrp and NPY in fastingactivated hypothalamic neurons. Nature neuroscience, 1(4): 271.

Holm, J. C., Gamborg, M., Ward, L. C., Gammeltoft, S., Kaas-Ibsen, K., Heitmann, B. L. \& Sørensen, T. I. 2011. Tracking of leptin, soluble leptin receptor, and the free leptin index during weight loss and regain in children. Obesity facts, 4(6): 461-468. 
Juonala, M., Magnussen, C. G., Berenson, G. S., Venn, A., Burns, T. L., Sabin, M. A., Srinivasan, S. R., Daniels, S. R., Davis, P. H., Chen, W. \& Sun, C. 2011. Childhood adiposity, adult adiposity, and cardiovascular risk factors. New England Journal of Medicine, 365(20): 1876-1885.

Kanoski, S. E., Hayes, M. R. \& Skibicka, K. P. 2016. GLP-1 and weight loss: unraveling the diverse neural circuitry. American Journal of Physiology-Regulatory, Integrative and Comparative Physiology, 310(10): R885-R895.

Knutson, K. L. \& Van C. E. 2008. Associations between sleep loss and increased risk of obesity and diabetes. Annals of the New York Academy of Sciences, 1129(1): 287-304.

Könner, A. C., Janoschek, R., Plum, L., Jordan, S. D., Rother, E., Ma, X., Xu, C., Enriori, P., Hampel, B., Barsh, G. S. \& Kahn, C. R. 2007. Insulin action in AgRP-expressing neurons is required for suppression of hepatic glucose production. Cell Metabolism, 5(6): 438-449.

Krahn, D. D., Gosnell, B. A., Levine, A. S. \& Morley, J. E. 1988. Behavioral effects of corticotropin-releasing factor: localization and characterization of central effects. Brain Research, 443: 63-69.

la Fleur, S. E., Akana, S. F., Manalo, S. L. \& Dallman, M. F. 2004. Interaction between corticosterone and insulin in obesity: regulation of lard intake and fat stores. Endocrinology, 145(5): 2174-2185.

Lange, D., Wahrendorf, M., Siegrist, J., Plachta-Danielzik, S., Landsberg, B. and Müller, M. J. 2011. Associations between neighborhood characteristics, body mass index and health-related behaviors of adolescents in the Kiel obesity prevention study: a multilevel analysis. European Journal of Clinical Nutrition, 65(6): 7-11.

Levin, B. E., Dunn-Meynell, A. A. \& Banks, W. A. 2004. Obesity-prone rats have normal blood-brain barrier transport but defective central leptin signaling before obesity onset. American Journal of Physiology-Regulatory, Integrative and Comparative Physiology, 286(1): R143-150.

Lupien, S. J., Parent, S., Evans, A. C., Tremblay, R. E., Zelazo, P. D., Corbo, V., Pruessner, J. C. \& Séguin, J. R. 2011. Larger amygdala but no change in hippocampal volume in 10-year-old children exposed to maternal depressive symptomatology since birth. Proceedings of the National Academy of Sciences, 108(34): 1432414329.

Maffei, M., Fei, H., Lee, G. H., Dani, C., Leroy, P., Zhang, Y., Proenca, R., Negrel, R., Ailhaud, G. \& Friedman, J. M. 1995. Increased expression in adipocytes of ob RNA in mice with lesions of the hypothalamus and with mutations at the db locus. Proceedings of the National Academy of Sciences, 92(15): 6957-6960.

McEwen, B. S. 2007. Physiology and neurobiology of stress and adaptation: central role of the brain. Physiological Reviews, 87(3): 873-904.

Nieuwenhuizen, A. G. \& Rutters, F. 2008. The hypothalamic-pituitary-adrenal-axis in the regulation of energy balance. Physiology \& Behavior, 94(2): 169-177. 
Obici, S., Feng, Z., Morgan, K., Stein, D., Karkanias, G. \& Rossetti, L. 2002. Central administration of oleic acid inhibits glucose production and food intake. Diabetes, 51(2): 271-275.

Ogier, V., Ziegler, O., Mejean, L., Nicolas, J. P. \& Stricker-Krongrad, A. 2002. Obesity is associated with decreasing levels of the circulating soluble leptin receptor in humans. International Journal of Obesity, 26(4): 496.

Pedersen, W. A., Wan, R. \& Mattson, M. P. 2001. Impact of aging on stress-responsive neuroendocrine systems. Mechanisms of ageing and development, 122(9): 963-983.

Pereira, C. D, Azevedo, I., Monteiro, R. \& Martins, M. J. 2012. 11 -Hydroxysteroid dehydrogenase type 1: relevance of its modulation in the pathophysiology of obesity, the metabolic syndrome and type 2 Diabetes mellitus. Diabetes, Obesity and Metabolism, 14(10): 869-881.

Reul, J. M., De Kloet, E. R. 1986. Anatomical resolution of two types of corticosterone receptor sites in rat brain with in vitro autoradiography and computerized image analysis. Journal of Steroid Biochemistry, 24(1): 269-272.

Rhee, S. D., Sung, Y. Y., Lee, Y. S., Kim, J. Y., Jung, W. H., Kim, M. J., Lee, M. S., Lee, M. K., Yang, S. D., Cheon, H. G. 2011. Obesity of TallyHO/JngJ mouse is due to increased food intake with early development of leptin resistance. Experimental and Clinical Endocrinology \& Diabetes, 119(04):243-251.

Richard, D., Ferland, J., Lalonde, J., Samson, P. \& Deshaies, Y. 2000. Influence of topiramate in the regulation of energy balance. Nutrition, 16(10):961-966.

Rohner-jeanrenaud, F. R., Walker, C. D., Greco-perotto, R. O. \& Jeanrenaud, B. 1989. Central corticotropin-releasing factor administration prevents the excessive body weight gain of genetically obese (fa/fa) rats. Endocrinology, 124(2):733-739.

Rohner-Jeanrenaud, F., Cusin, I., Sainsbury, A., Zakrzowska, K. E. \& Jeanrenaud, B. 1996. The loop system between neuropeptide Y and leptin in normal and obese rodents. Hormone And Metabolic Research, 28(12):642-648.

Roper, J. A., O'Carroll, A. M., Young, W. S. \& Lolait, S. J. 2011. The vasopressin Avpr1b receptor: molecular and pharmacological studies. Stress, 14(1):98-115.

Sandeep, T. C., Andrew, R., Homer, N. Z., Andrews, R. C., Smith, K., Walker, B. R. 2005. Increased in vivo regeneration of cortisol in adipose tissue in human obesity and effects of the $11 \beta$-hydroxysteroid dehydrogenase type 1 inhibitor carbenoxolone. Diabetes, 54(3):872-879.

Sargent, B. J. \& Moore, N. A. 2009. New central targets for the treatment of obesity. British Journal Of Clinical Pharmacology, 68(6):852-860.

Sato, I., Arima, H., Ozaki, N., Watanabe, M., Goto, M., Hayashi, M., Banno, R., Nagasaki, H. \& Oiso, Y. 2005. Insulin inhibits neuropeptide Y gene expression in the arcuate nucleus through GABAergic systems. Journal of Neuroscience, 25(38):8657-864. 
Schwartz, M. W., Seeley, R. J., Campfield, L. A., Burn, P. \& Baskin, D. G. 1996. Identification of targets of leptin action in rat hypothalamus. The Journal of Clinical Investigation, 98(5):1101-1106.

Schwartz, M. W. 2000. Staying slim with insulin in mind. Science, 289(5487):2066-2067.

Schwartz, M. W., Woods, S. C., Seeley, R. J., Barsh, G. S., Baskin, D. G. \& Leibel, R. L. 2003. Is the energy homeostasis system inherently biased toward weight gain?. Diabetes, 52(2):232-238.

Sinha, M. K., Ohannesian, J. P., Heiman, M. L., Kriauciunas, A., Stephens, T. W., Magosin, S., Marco, C. \& Caro, J. F. 1996. Nocturnal rise of leptin in lean, obese, and non-insulin-dependent Diabetes mellitus subjects. The Journal of Clinical Investigation. 97(5):1344-1347.

Sipols, A. J., Baskin, D. G. \& Schwartz, M. W. 1995. Effect of intracerebroventricular insulin infusion on diabetic hyperphagia and hypothalamic neuropeptide gene expression. Diabetes, 44(2):147-151.

Stephens, T. W., Basinski, M., Bristow, P. K., Bue-Valleskey, J. M., Burgett, S. G., Craft, L., Hale, J., Hoffmann, J., Hsiung, H. M., Kriauciunas, A. \& MacKellar, W. 1995. The role of neuropeptide Y in the antiobesity action of the obese gene product. Nature, 377(6549):530-531.

Taheri, S., Lin, L., Austin, D., Young, T. \& Mignot, E. 2004. Short sleep duration is associated with reduced leptin, elevated ghrelin, and increased body mass index. PLoS Medicine, 1(3):e62.

Tasker, J. G. 2006. Rapid glucocorticoid actions in the hypothalamus as a mechanism of homeostatic integration. Obesity, 14(S8):259S-265S.

Tremblay, A., Pérusse, L. \& Bouchard, C. 2004. Energy balance and body-weight stability: impact of geneenvironment interactions. British Journal of Nutrition, 92(S1):S63-S66.

Tsigos, C. \& Chrousos, G. P. 2002. Hypothalamic-pituitary-adrenal axis, neuroendocrine factors and stress. Journal of Psychosomatic Research, 53(4):865-871.

Wadden, T. A., Hollander, P., Klein, S., Niswender, K., Woo, V., Hale, P. M. \& Aronne, L. 2015. Weight maintenance and additional weight loss with liraglutide after low-calorie-diet-induced weight loss: The SCALE Maintenance randomized study. International Journal of Obesity, 39(1):187-188.

Wang, Q., Bing, C., Al-Barazanji, K., Mossakowaska, D. E., Wang, X. M., McBay, D. L., Neville, W. A., Taddayon, M., Pickavance, L., Dryden, S. \& Thomas, M. E. 1997. Interactions between leptin and hypothalamic neuropeptide Y neurons in the control of food intake and energy homeostasis in the rat. Diabetes, 46(3):335341.

Warne, J. P. 2009. Shaping the stress response: interplay of palatable food choices, glucocorticoids, insulin and abdominal obesity. Molecular and Cellular Endocrinology, 300(1-2):137-146. 
Wolkowitz, O. M., Burke, H., Epel, E. S. \& Reus, VI. 2009. Glucocorticoids. Annals of the New York Academy of Sciences, 1179(1):19-40.

Yen SS, Laughlin GA. Aging and the adrenal cortex. Experimental gerontology. 1998 Nov 1;33(7-8):897-910.

Yi, C. X., Foppen, E., Abplanalp, W., Gao, Y., Alkemade, A., La Fleur, S. E., Serlie, M. J., Fliers, E., Buijs, R. M., Tschöp, M. H. \& Kalsbeek, A. 2012. Glucocorticoid signaling in the arcuate nucleus modulates hepatic insulin sensitivity. Diabetes, 61(2):339-345.

Zhang, Y., Proenca, R., Maffei, M., Barone, M., Leopold, L. \& Friedman, J. M. 1994. Positional cloning of the mouse obese gene and its human homologue. Nature, 372(6505):425. 